\title{
Intrathecal morphine provides better postopera- tive analgesia than psoas compartment block after primary hip arthroplasty
}

[L'administration intrathécale de morphine procure une meilleure analgésie postopératoire que le bloc du plexus lombaire à la suite d'une arthroplastie primaire de la hanche] Vincent Souron MD, ${ }^{*}$ Laurent Delaunay MD, ${ }^{*}$ Patrick Schifrine MD $\dagger$

Purpose: Intrathecal morphine and psoas compartment block represent two accepted techniques to provide postoperative analgesia after hip arthroplasty. We designed a prospective, randomized, single-blinded study to compare these two techniques.

Methods: Patients scheduled for primary hip arthroplasty under general anesthesia were randomized to receive either an intrathecal administration of $0.1 \mathrm{mg}$ morphine (Group I, $n=27$ ) or a psoas compartment block with ropivacaine $0.475 \% 25 \mathrm{~mL}$ (Group II, n $=26$ ). Pain scores, morphine consumption, associated side-effects were assessed for $48 \mathrm{hr}$ postoperatively. In addition, patient's acceptance and satisfaction of the postoperative analgesic technique were also recorded.

Results: During the first $24 \mathrm{hr}$, pain scores $(3.3 \pm 9.6 \mathrm{~mm}$ vs 22.8 $\pm 27 . \mathrm{l}$ at $\mathrm{H}+6,3.3 \pm 8.3 \mathrm{~mm}$ vs $25 \pm 26.7 \mathrm{~mm}$ at $\mathrm{H}+\mathrm{I} 2,7 \pm$ $14.9 \mathrm{~mm}$ vs $21.9 \pm 29 \mathrm{~mm}$ at $\mathrm{H}+18$ ) and morphine consumption $(0.56 \pm 2.12 \mathrm{mg}$ vs $9.42 \pm 10.13 \mathrm{mg})$ were lower in Group I than in Group II. Urinary retention was the more frequent side-effect occurring in 37\% of cases in Group I vs 1 I.5\% in Group II ( $P<$ 0.05). No major complication occurred. Despite better analgesia provided by the use of intrathecal morphine, there was no difference in the satisfaction scores between groups.

Conclusion: $0.1 \mathrm{mg}$ intrathecal morphine administration provides better postoperative analgesia than single-shot psoas compartment block after primary hip arthroplasty.

Objectif : La rachianalgésie morphinique et le bloc du plexus lombaire par voie postérieure sont deux techniques adéquates pour assurer l'analgésie postopératoire après la mise en place d'une prothèse totale de hanche. Dans cette étude, ces deux techniques sont comparées de manière prospective, randomisée et simple aveugle.

Méthode : Avant l'anesthésie générale, les patients étaient tirés au sort pour recevoir soit une injection intrathécale lombaire de $0,1 \mathrm{mg}$ de morphine (Groupe I, $n=27$ ), soit un bloc du plexus lombaire par voie postérieure avec injection unique de $25 \mathrm{~mL}$ de ropivacaïne à 0,475 \% (Groupe II, $n=26$ ). Les scores de douleur, la consommation de morphine et les effets secondaires étaient évalués pendant les 48 premières heures postopératoires. De plus, l'acceptation par le patient de la technique analgésique et sa satisfaction pour la prise en charge de la douleur postopératoire étaient également comparées.

Résultats : Dans les 24 premières heures, les scores de douleur (3,3 $\pm 9,6 \mathrm{~mm}$ vs $22,8 \pm 27,1$ à $\mathrm{H}+6 ; 3,3 \pm 8,3 \mathrm{~mm}$ vs $25 \pm 26,7$ $\mathrm{mm}$ à $\mathrm{H}+12 ; 7 \pm 14,9 \mathrm{~mm}$ vs $21,9 \pm 29 \mathrm{~mm}$ à $\mathrm{H}+18)$ et la consommation de morphine $(0,56 \pm 2,12 \mathrm{mg}$ vs 9,42 $\pm 10,13 \mathrm{mg})$ étaient significativement moins élevés dans le Groupe I que dans le Groupe II. La rétention urinaire était plus fréquente dans le Groupe I (37\% vs 1/,5\%). Aucune complication grave n'est survenue. En dépit d'une meilleure analgésie procurée par la rachianalgésie morphinique, la satisfaction était comparable dans les deux groupes.

Conclusion : La conclusion principale de cette étude est que la rachianalgésie morphinique procure une meilleure analgésie postopératoire que le bloc du plexus lombaire par voie postérieure en injection unique après la mise en place d'une prothèse totale de hanche.

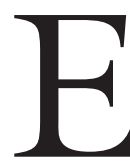

VIDENCE supports the concept that there is a relationship between the quality of the postoperative analgesia and the immediate functional outcome following major orthopedic surgery. ${ }^{1,2}$ In this regard, intrathecal administration of morphine has been shown to provide adequate pain control after hip arthroplasty. ${ }^{3,4}$ However, this technique is known to be associated with unpleasant side-effects (nausea and vomiting, itching, urinary

From the Departments of Anesthesiology, ${ }^{*}$ and Orthopedic Surgery, $†$ Clinique Générale, Annecy, France.

Address correspondence to: Dr. Vincent Souron, Department of Anesthesiology, Clinique Générale, 4, chemin de la tour La Reine,

74000 Annecy, France. Phone: 33 (0)4 503303 20; Fax: 33 (0)4 503303 21; E-mail: vsouron@club-internet.fr

Accepted for publication September 26, 2002.

Revision accepted March 12, 2003. 
retention) or life-threatening respiratory depression. In a dose-finding study, Slappendel et al. demonstrated that $0.1 \mathrm{mg}$ of intrathecal morphine is the dose providing optimum postoperative pain relief with minimal side effects. ${ }^{5}$

The psoas compartment block, a technique associated with a complete block of the branches of the lumbar plexus (femoral nerve, obturator nerve, lateral femoral cutaneous nerve) involved in the innervation the hip, has also been demonstrated to be effective for postoperative analgesia after hip arthroplasty. ${ }^{6}$ However, rare but serious complications reported in the literature (total spinal anesthesia, renal or psoas hematoma) require that the psoas compartment block be revisited in terms of pain relief after total hip arthoplasty. ${ }^{7-10}$

Therefore, we designed a randomized single-blinded study to compare intrathecal morphine with psoas compartment block for postoperative analgesia after hip arthroplasty.

\section{Patients and methods}

Fifty-six patients ASA physical status I-II with advanced osteoarthritis of the hip scheduled for primary unilateral hip arthroplasty (cemented prosthesis, posterior approach) under general anesthesia were included in this prospective, randomized and singleblinded study. Our local Ethics Committee approved the protocol. After appropriate informed consents were obtained, the patients were randomly assigned to one of two groups (sealed envelopes): Group I (intrathecal morphine) or Group II (psoas compartment block).

Exclusion criteria included: renal dysfunction, allergy to morphine, local anesthetics, non-steroidal antiinflammatory drugs and propacetamol, preoperative respiratory insufficiency, coagulopathy, and/or treatment with anticoagulants or aspirin.

All patients received $1 \mathrm{mg} \cdot \mathrm{kg}^{-1}$ of hydoxyzine orally two hours before surgery. Prior to surgery, an 18-gauge catheter was inserted in the forearm, a crystalloid infusion was started $(500 \mathrm{~mL}$ over $45 \mathrm{~min})$ and then left at the anesthesiologist's discretion. Vital signs were obtained (electrocardiogram, pulse oxymetry and arterial blood pressure). Within $30 \mathrm{~min}$ before general anesthesia, a senior anesthesiologist - V.S. or L.D - (highly trained in both techniques and not involved in the postoperative evaluation of the patients) performed either a spinal or a psoas compartment block. Accordingly, in Group I (intrathecal morphine) the patients were placed in the sitting position and after local anesthesia of the skin ( $3 \mathrm{~mL}$ of lidocaine $2 \%$ ), a dural puncture was performed with a 25-gauge spinal needle (Sprotte®; Pajunk, Melsungen, Germany) at the L4-L5 inter-ver- tebral space. Aspiration of cerebrospinal fluid confirmed the adequate placement of the needle. This was followed by the administration of $0.1 \mathrm{mg}$ of morphine without preservative in $1 \mathrm{~mL}$ saline solution over 15 sec. In Group II, the patients were placed in the lateral position with the operated hip uppermost. After local anesthesia of the skin ( $3 \mathrm{~mL}$ of lidocaine $2 \%$ ), a psoas compartment block was performed according to the landmarks described by Winnie. ${ }^{11}$ A 20 -gauge insulated 100-mm b-bevelled needle (Uniplex®; Pajunk, Melsungen, Germany) connected to a nerve stimulator (Stimuplex-DIG®; Braun, Geisingen, Germany) set up to deliver $1.5 \mathrm{~mA}, 2 \mathrm{~Hz}$ and $0.1 \mathrm{msec}$ was introduced perpendicularly to the skin until a stimulation of the femoral nerve was obtained. The position of the needle was adjusted to maintain the same motor response (contraction of the quadriceps muscle associated with movement of the patella) with a current of $0.5 \mathrm{~mA}$ or less. After negative blood aspiration, $25 \mathrm{~mL}$ of ropivacaine $0.475 \%$ (mixture of ropivacaine $0.2 \%$ and ropivacaine $0.75 \%$ ) were slowly injected. The intensity of the block was confirmed postoperatively by pinprick test in the femoral nerve territory (anterior aspect of the thigh). During the performance of regional anesthesia (intrathecal morphine or psoas block), the following variables were recorded: number of attempts, duration of the procedure (from the introduction of the needle to its removal), pain score during the procedure using a visual analogue scale (VAS) ranging from $0 \mathrm{~mm}$ (no pain) to $100 \mathrm{~mm}$ (worst imaginable pain), technical problems (paresthesias, blood aspiration, failure...).

In both groups, general anesthesia was induced by an anesthesiologist blinded to group assignment with propofol $\left(2 \mathrm{mg} \cdot \mathrm{kg}^{-1}\right)$, atracurium $\left(0.5 \mathrm{mg} \cdot \mathrm{kg}^{-1}\right)$ and sufentanil $\left(0.3 \mu \mathrm{g} \cdot \mathrm{kg}^{-1}\right)$. The trachea was intubated and anesthesia maintained with nitrous oxide $(60 \%)$, oxygen (40\%), sevoflurane $1 \%-1.5 \%$ end-tidal concentration and sufentanil (supplemental boluses $0.1 \mu \mathrm{g} \cdot \mathrm{kg}^{-1}$ last bolus $30 \mathrm{~min}$ before the end of surgery) according to clinical needs. Maintenance of anesthesia and fluid loading were left at the anesthesiologist's discretion.

Two hours after recovery, the patients left the postanesthesia care unit for a conventional hospitalization ward. They received $3 \mathrm{~L} \cdot \mathrm{min}^{-1}$ of oxygen for the first $24 \mathrm{hr}$. Postoperative pain was assessed with VAS every 30 min during two hours, every six hours during $24 \mathrm{hr}$ and at $48 \mathrm{hr}$. When VAS was $>30 \mathrm{~mm}$ at rest, supplemental morphine was given as a rescue analgesic: intravenously ( $3 \mathrm{mg}-$ or $2 \mathrm{mg}$ if age more than $70 \mathrm{yr}$ ) every five minutes in the postanesthesia care unit and subcutaneously (10 $\mathrm{mg}$ - or $5 \mathrm{mg}$ if age more than 70 yr) every six hours (maximum every four hours) on the ward. Postoperatively, propaceta- 
TABLE I Demographic data

\begin{tabular}{|c|c|c|}
\hline & Intrathecal morphine & Psoas block \\
\hline$n$ & 27 & 26 \\
\hline Age $(y r)$ & $66.8 \pm 13.1$ & $67.7 \pm 12$ \\
\hline Gender $(\mathrm{m} / \mathrm{f})$ & $12 / 14$ & $9 / 18$ \\
\hline Height $(\mathrm{cm})$ & $165.8 \pm 8.4$ & $158 \pm 29.6$ \\
\hline Weight $(\mathrm{kg})$ & $73.8 \pm 14.7$ & $74.1 \pm 17.3$ \\
\hline Intraoperative sufentanil $(\mu \mathrm{g})$ & $20 \pm 4.3$ & $22.5 \pm 7.5$ \\
\hline
\end{tabular}

Values are mean $\pm \mathrm{SD}(P=\mathrm{NS})$.

TABLE II Technical characteristics

\begin{tabular}{lll}
\hline & Intrathecal morphine & Psoas block \\
\hline $\begin{array}{l}\text { Number of attempts } \\
\begin{array}{l}\text { Duration of } \\
\text { procedure }(\mathrm{sec})\end{array}\end{array}$ & $1.56 \pm 0.93$ & $1.65 \pm 1.32$ \\
$\begin{array}{l}\text { VAS during } \\
\text { procedure }(\mathrm{mm})\end{array}$ & $10.12 \pm 16.26^{*}$ & $22.92 \pm 22.55$ \\
$\begin{array}{l}\text { Problems during } \\
\text { procedure }\end{array}$ & 0 & 2 blood aspirations \\
\hline
\end{tabular}

VAS $=$ visual analogue scale; Values are mean $\pm S \mathrm{D}\left({ }^{*} P<0.05\right)$.

TABLE III Side effects

\begin{tabular}{lll}
\hline & Intrathecal morphine & Psoas block \\
\hline $\begin{array}{l}\text { Urinary retention } \\
\text { Urinary drainage } \\
\text { (in case of naloxone }\end{array}$ & $10(37)^{*}$ & $3(11.5)$ \\
inefficiency) & $4(14.8)^{*}$ & \\
Itching & $5(18.5)$ & $2(7.7)$ \\
Nausea & $3(11.1)$ & $1(3.8)$ \\
Vomiting & $4(14.8)$ & $4(15.4)$ \\
Uncomfortable & & $4(15.4)$ \\
motor block & $0(0)$ & $6(23)^{*}$ \\
$\begin{array}{l}\text { Sudden resolution } \\
\text { of analgesia }\end{array}$ & $0(0)$ & $3(11.5)^{*}$ \\
$\begin{array}{l}\text { Respiratory rate } \leq 10 \\
\text { Headache }\end{array}$ & $0(0)$ & $0(0)$ \\
Epidural anesthesia & $0(0)$ & $0(0)$ \\
\hline
\end{tabular}

Values are $n$ and percentage as required $\left({ }^{*} P<0.05\right)$.

mol (2 $\mathrm{g} i v$ four times daily) and ketoprofen (100 mg iv twice daily) were administered to all patients during the study period. In case of urinary retention, iv naloxone $0.2 \mathrm{mg}$ was administered. If the patient remained unable to void, the bladder was catheterized. Major arterial hypotension was defined as an hypotension requiring unusual amounts of iv ephedrine and/or fluids.

Morphine consumption in the postanesthesia care unit, and during the first 24 and $48 \mathrm{hr}$ were recorded. In addition, postoperative itching, urinary retention, nausea, vomiting, respiratory depression (respiratory

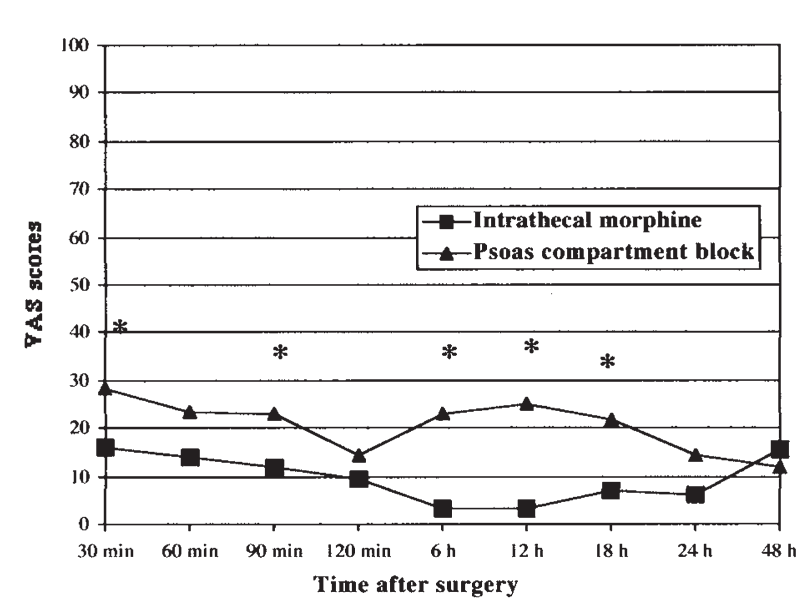

FIGURE 1 Mean visual analogue scale (VAS) pain scores during the first $48 \mathrm{hr}$ after surgery. ${ }^{*} P<0.05$ between groups.

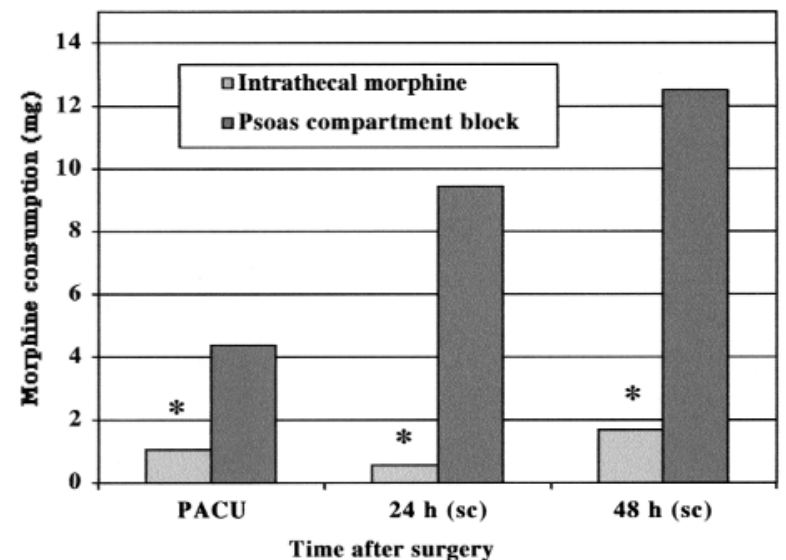

FIGURE 2 Cumulative morphine consumption during $48 \mathrm{hr}$ after surgery given as mean, $i v$ in recovery room, $s c$ in hospitalization ward at $24 \mathrm{hr}$ (from $\mathrm{H} 0$ to $\mathrm{H} 24$ ) and at $48 \mathrm{hr}$ (from H0 to H48). ${ }^{*} P<0.05$. PACU $=$ postanesthesia care unit.

rate less than $10 \mathrm{~min}^{-1}$ ), epidural anesthesia, excessive sedation, major arterial hypotension and headache were recorded. At the end of the study period, patients were questioned about their satisfaction with the management of postoperative pain. Satisfaction was measured with a VAS from 0 (absolutely not satisfied with pain management) to 100 (entirely satisfied with pain management). 
Data are presented as mean \pm SD. Statistical analyses were performed using Student's t test or Chi square as required. A $P$ value $<0.05$ was considered significant.

\section{Results}

Demographic data are presented in Table I. There was no difference in age, height, weight, gender and intraoperative sufentanil requirements.

Technical characteristics of the regional techniques are shown in Table II. The number of attempts was similar. Dural puncture was successful in all patients in Group I and femoral block was effective in all patients in Group II. The difference between the duration of each procedure was not statistically significant.

The frequency and types of adverse effects are presented in Table III. Incidence of itching, nausea and vomiting was not different among the groups. Incidence of urinary retention with or without catheterization was higher in Group I. No episodes of excessive sedation, respiratory depression or major hypotension were recorded.

The VAS pain scores are shown in Figure 1. Morphine consumption is shown in Figure 2. Morphine consumption was lower in Group I than in Group II: $1.07 \pm 2.79 \mathrm{mg}$ vs $4.38 \pm 6.32 \mathrm{mg}$ in the postanesthesia care unit, $0.56 \pm 2.12 \mathrm{mg}$ vs $9.42 \pm$ $10.13 \mathrm{mg}$ during the first $24 \mathrm{hr}, 1.67 \pm 4.8 \mathrm{mg}$ vs 12.50 $\pm 14.98 \mathrm{mg}$ during the first $48 \mathrm{hr}(P<0.05)$. The number of patients receiving $s c$ morphine during the first 24 hr was higher in the psoas compartment group (17/26 vs $2 / 27 ; P<0.05)$. Satisfaction scores were not statistically different $(91.74 \pm 14.03 \mathrm{~mm}$ in Group I ps 84.79 $\pm 14.41 \mathrm{~mm}$ in Group II).

\section{Discussion}

Our study indicates that intrathecal morphine provides better postoperative analgesia than psoas compartment block after primary total hip arthroplasty. Except for a higher frequency of urinary retention, this technique was not associated with more frequent adverse effects. No major complications were observed with either technique.

The innervation of the hip does not depend only on the lumbar plexus, but also on the sacral plexus that gives sensitive afferents to the acetabulum and to the articular capsula. ${ }^{12}$ Consequently, it is unlikely that a psoas compartment block can provide complete anesthesia and/or analgesia of the hip without a combined sciatic nerve block. Thus, as a sole anesthesia technique, a psoas compartment block has been shown to fail to achieve surgical anesthesia for hip fracture surgery in $85 \%$ of cases. ${ }^{13}$ The median VAS values in the psoas group were consistent with those previously recorded by Stevens et al..$^{6}$ In our study, the psoas compartment block was less effective than the intrathecal morphine as indicated by higher VAS scores and fifteenfold higher morphine requirements in the first $24 \mathrm{hr}$.

After the first postoperative day, the morphine requirements were minimal and no difference between groups was recorded. At 24 and $48 \mathrm{hr}$, the mean VAS values of pain at rest were less than $20 \mathrm{~mm}$ with both techniques. Our study confirms that most of the pain occurs during the first $24 \mathrm{hr}$ following hip arthroplasty. ${ }^{14}$ Consequently, we suggest that no sophisticated analgesia technique is needed $24 \mathrm{hr}$ after primary total hip replacement. Although attractive, ${ }^{15,16}$ the use of continuous peripheral nerve blocks (three-in-one or psoas compartment block via a perineural catheter) remains a subject of debate (except probably for hip revision surgery).

Urinary retention was the most important side-effect associated with the use of intrathecal morphine. Bladder catheterization may lead to urinary tract infection $(0.5$ to $20 \%$ per catheterization), possible hematogenous infection of the joint ${ }^{17}$ and urethral stenosis. Slappendel et al. have reported an incidence of urinary retention of more than $70 \%{ }^{5}$ In our study, we found an incidence of $37 \%$ of urinary retentions vs $11.5 \%$ in the psoas compartment block group (only 14.8\% required catheterization $v s 7.7 \%$ in the psoas compartment block group). The administration of naloxone was not associated with exacerbation of pain in patients having urinary retention. Intrathecal morphine was also associated with a higher incidence of itching ( $18.5 \%$ vs 3.5\% in the psoas compartment group), but this difference was not statistically significant. The incidence of vomiting did not differ between groups. We conclude that the increased incidence of urinary retention and, possibly, severe itching represents the main concern with intrathecal morphine. Psoas compartment blocks appeared to be safe in our study. Epidural block did not occur, in contrast with the previously recorded percentages of 4 to $10 \%{ }^{16}$ However, the number of patients studied was small.

Patient acceptance of regional techniques depends on different factors, such as the number of nerve stimulations, intensity of stimulation, electrical paresthe$\operatorname{sia}(\mathrm{s})$, repeated needle insertions, infiltration of needle puncture site(s) with local anesthetics, muscle contractions, bony contacts and associated sedation..$^{18,19}$ Pain and/or discomfort may lead to patient dissatisfaction or rejection of the technique for future operations. Pain due to the regional technique was higher with the psoas compartment block compared to spinal analgesia, probably because performance of the psoas compartment block is associated with uncomfortable electrical sensations. 
Despite the major differences between groups concerning the quality of analgesia, satisfaction scores were comparable and quite high. More frequent adverse effects with intrathecal morphine may explain this lack of difference between groups. However, satisfaction with regional analgesia is a complex phenomenon that cannot be assessed well by a single global measurement, such as a VAS, which generally results in high satisfaction ratings. ${ }^{20}$ Although regional anesthesia improves patient outcome, it is not clear whether use of regional analgesia improves patient satisfaction. ${ }^{21}$ The comparison of two regional techniques usually fails to demonstrate any significant differences with regard to the degree of patient satisfaction..$^{21}$ Furthermore, Le May et al. have demonstrated the absence of appropriate instruments to measure patient satisfaction with anesthesia services. ${ }^{22}$ The reduction of the side-effects associated with low doses of intrathecal morphine (urinary retention, itching) could improve satisfaction with this technique. The incidence of side-effects is decreased with lower doses of intrathecal morphine, but the quality of postoperative analgesia decreases also. ${ }^{5}$

In summary, intrathecal morphine provides better postoperative analgesia after primary hip arthroplasty than psoas compartment block. Although VAS pain scores during performance of the blocks and in the postoperative period were lower with intrathecal morphine, satisfaction with pain management was similar in both groups.

\section{Acknowledgement}

The authors would like to thank Dr J.E. Chelly for his reviewing of this manuscript.

\section{References}

1 Capdevilla X, Barthelet $\Upsilon$, Biboulet P, Ryckwaert $\Upsilon$, Rubenovitch $J$, d'Athis F. Effects of perioperative analgesic technique on the surgical outcome and duration of rehabilitation after major knee surgery.

Anesthesiology 1999; 91: 8-15.

2 Chelly JE, Greger J, Gebhard R, et al. Continuous femoral blocks improve recovery and outcome of patients undergoing total knee arthroplasty. J Arthroplasty 2001; 16: 436-45.

3 Grace D, Fee JPH. A comparison of intrathecal morphine-6-glucuronide and intrathecal morphine sulfate as analgesics for total hip replacement. Anesth Analg 1996; 83: 1055-9.

4 Reay BA, Semple AJ, Macrae WA, MacKenzie N, Grant IS. Low-dose intrathecal diamorphine analgesia following major orthopaedic surgery. Br J Anaesth 1989; 62: 248-52.

5 Slappendel R, Weber EWG, Dirksen R, Gielen MJM, van
Limbeek J. Optimization of the dose of intrathecal morphine in total hip surgery: a dose-finding study. Anesth Analg 1999; 88: 822-6.

6 Stevens RD, Van Gessel E, Flory N, Fournier R, Gamulin $Z$. Lumbar plexus block reduces pain and blood loss associated with total hip arthroplasty. Anesthesiology 2000; 93: 115-21.

7 Aida S, Takabashi H, Shimoji K. Renal subcapsular hematoma after lumbar plexus block. Anesthesiology 1996; 84: 452-5.

8 Klein SM, D'Ercole F, Greengrass RA, Warner DS. Enoxaparin associated with psoas hematoma and lumbar plexopathy after lumbar plexus block.

Anesthesiology 1997; 87: 1576-9.

9 Gentili M, Aveline C, Bonnet F. Total spinal anesthesia after posterior lumbar plexus block (French). Ann Fr Anesth Réanim 1998; 17: 740-2.

10 Pham-Dang C, Beaumont S, Floch H, Bodin J, Winer A, Pinand $M$. Acute toxic accident following lumbar plexus block with bupivacaine (French). Ann Fr Anesth Réanim 2000; 19: 356-9.

11 Winnie AP. Regional anesthesia. Surg Clin North Am 1975; 54: 861-92.

12 Testud L. Système Nerveux Périphériques, Organe des Sens, Appareil de la Respiration et de la Phonation. Traité d'Anatomie Humaine, tome 3. Lyon; 1922.

13 Chudinov A, Berkenstadt H, Salai M, Cahana A, Perel $A$. Continuous psoas compartment block for anesthesia and perioperative analgesia in patients for hip fractures. Reg Anesth Pain Med 1999; 24: 563-8.

14 Benedetti C, Bonica JJ, Belluci G. Pathophysiology and therapy of postoperative pain: a review. In: Benedetti C, Bonica JJ, Belluci G. (Eds.). Advances in Pain Research and Therapy, vol. 7. New York: Raven Press; 1984: 373-407.

15 Singelyn FJ, Vanderelst PE, Gouverneur JMA. Extended femoral nerve sheath block after total hip arthroplasty: continuous versus patient-controlled techniques.

Anesth Analg 2001; 92: 455-9.

16 Capdevilla X, Macaire P, Dadure C, et al. Continuous psoas compartment block for postoperative analgesia after total hip arthroplasty: new landmarks, technical guidelines, and clinical evaluation. Anesth Analg 2002; 94: 1606-13.

17 Michelson JD, Lotke PA, Steinberg ME. Urinary-bladder management after total joint-replacement surgery. N Engl J Med 1988; 319: 321-6.

18 Kinirons BP, Bonaziz H, Paqueron X, et al. Sedation with sufentanil and midazolam decreases pain in patients undergoing upper limb surgery under multiple nerve block. Anesth Analg 2000; 90: 1118-21.

19 Koscielniak-Nielsen ZJ, Rassmussen H, Jepsen K. Effects of impulse duration on patients' perception of electrical 
stimulation and block effectiveness during axillary block in unsedated ambulatory patients. Reg Anesth Pain Med 2001; 26: 428-33.

20 Fung D, Cohen MM. Measuring patient satisfaction with anesthesia care: a review of current methodology. Anesth Analg 1998; 87: 1089-98.

$21 W u$ CL, Naqibuddin M, Fleisher LA. Measurements of patient satisfaction as an outcome of regional anesthesia and analgesia: a systematic review. Reg Anesth Pain Med 2001; 26: 196-208.

22 Le May S, Hardy JF, Taillefer MC, Dupuis G. Patient satisfaction with anesthesia services. Can J Anesth 2001; 48: 153-62.

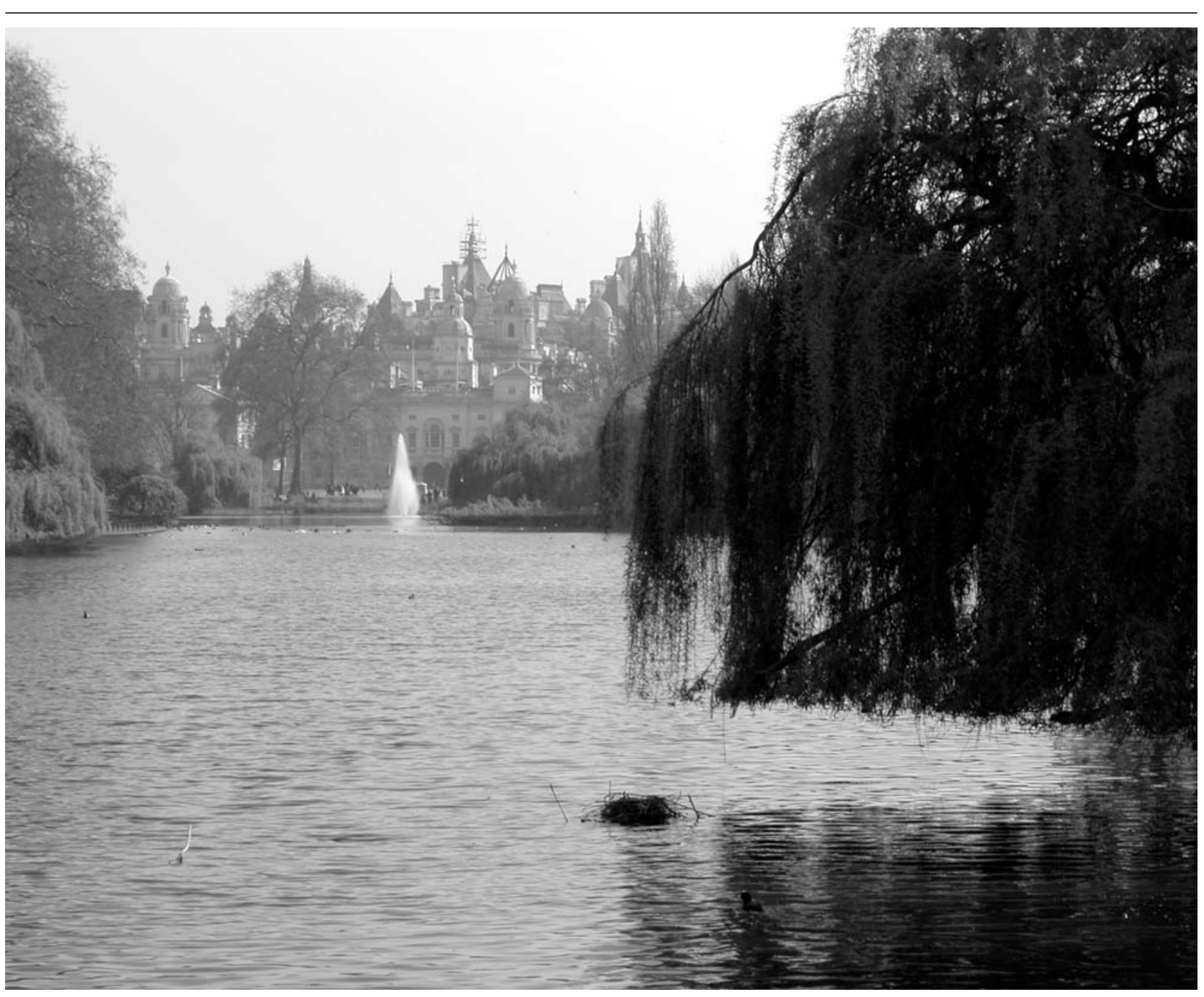

St. James' Park - London. UK 